\title{
chaJOPEN
}

\section{Off-label postpartum use of domperidone in Canada: a multidatabase cohort study}

\author{
Carolina Moriello MSc, J. Michael Paterson MSc, Pauline Reynier MSc, Matthew Dahl BSc, \\ Wusiman Aibibula MD PhD, Anat Fisher MD PhD, John-Michael Gamble BSc(Pharm) PhD, \\ I fan Kuo PharmD MSc, Paul E. Ronksley PhD, Brandace Winquist PhD, Kristian B. Filion PhD; \\ for the Canadian Network for Observational Drug Effect Studies (CNODES) Investigators*
}

\section{Abstract}

Background: Trends in off-label postpartum use of domperidone and the impact of safety advisories on its use remain unknown. Our objectives were to describe postpartum use of domperidone in Canada, to evaluate the impact of Health Canada advisories on prescribing patterns, and to describe the association between domperidone use and a composite end point of sudden cardiac death or ventricular tachycardia (VT) among postpartum patients.

Methods: We conducted a multidatabase cohort study involving pregnant patients with live births between 2004 and 2017 using administrative health databases from 5 Canadian provinces (British Columbia, Alberta, Saskatchewan, Manitoba and Ontario). We excluded patients with less than 1 year of prepregnancy database history and with approved indications for domperidone. We assessed domperidone use in the 6 months postpartum and the impact of the 2012 and 2015 Health Canada advisories on prescribing via interrupted time series analysis. We estimated crude rates of VT and sudden cardiac death.

Results: We included 1190987 live births. Mean maternal age was 28.6 (standard error 0.6) years. Domperidone use increased over time, from 7\% in 2003-2005 to 12\% in 2009-2011, when it plateaued. The 2012 advisory was followed by a drop in use and a reduction in slope, and the 2015 advisory had a more modest impact. Crude analysis suggests that domperidone may be associated with increased VT or sudden cardiac death (0.74 v. 0.37 per 10000 person-years; difference per 10000 person-years: 0.37 , $95 \%$ confidence interval -0.67 to 1.41 ).

Interpretation: Postpartum domperidone use increased between 2004 and 2017, with prescribing attenuated after Health Canada advisories and a very low absolute rate of VT or sudden cardiac death. These findings suggest that Health Canada advisories affected prescribing; any potential increase in VT or sudden cardiac death with use of domperidone is small and could not be confirmed in this large study. Study registration: ClinicalTrials.gov, no. NCT04024865

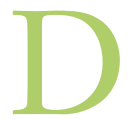
omperidone is an antiemetic and prokinetic drug prescribed for nausea, vomiting and dyspepsia related to motility disorders. ${ }^{1}$ Given its dopamine antagonist action, domperidone increases prolactin concentration and augments lactation. ${ }^{2}$ Consequently, it is often used off label to promote lactation among postpartum patients with insufficient supply of breast milk. A population-based study reported a substantial and growing frequency of postpartum domperidone use between 2002 and 2011 in British Columbia, with about $20 \%$ of patients in 2011 filling at least 1 prescription in the first 6 months postpartum. ${ }^{3}$ However, trends in postpartum use of domperidone in more recent years and in other jurisdictions remain understudied.

The increasing use of domperidone has coincided with concerns regarding its cardiac safety. ${ }^{4-8}$ Cardiac events of concern include QT interval prolongation, torsades de pointes, serious ventricular arrhythmia and sudden cardiac death. The US Food and Drug Administration issued warnings regarding domperidone's unapproved use to increase milk production in 2004. Health Canada issued advisories regarding domperidone's cardiac risks in March 2012 and January 2015,9,10 and the European Medicines Agency (EMA) released its recommendations in March 2014. ${ }^{11}$ These safety advisories were based on evidence of increased arrhythmic events among older adults, who typically have a

\section{Competing interests: None declared.}

This article has been peer reviewed.

*See end of article for investigators.

Correspondence to: Kristian Filion, kristian.filion@mcgill.ca

CMAJ Open 2021. DOI:10.9778/cmajo.20200084 
large comorbidity burden and frequent comedication use. However, evidence regarding the safety of domperidone in other populations such as postpartum patients, who may be less susceptible to its QT interval-prolonging effects, remains limited. The association between domperidone and cardiac events has been examined in a previous observational study involving postpartum patients. ${ }^{11}$ Although the study identified a signal of potential harm (hazard ratio [HR] 2.25, $95 \%$ confidence interval [CI] 0.84 to 6.01 ), methodological limitations (i.e., exposure misclassification, outcome misclassification and imprecise estimates) render the study's results difficult to interpret.

Our objectives were to describe domperidone use among postpartum patients in Canada, to evaluate the impact of the Health Canada advisories on prescribing patterns, and to describe the association between domperidone use and the risk of a composite end point of sudden cardiac death or ventricular tachycardia (VT) among postpartum patients.

\section{Methods}

\section{Study design}

This study was conducted by the Canadian Network for Observational Drug Effect Studies (CNODES). ${ }^{12}$ We conducted a multidatabase retrospective cohort study using administrative health databases from 5 Canadian provinces (BC, Alberta, Saskatchewan, Manitoba and Ontario), following a common protocol with distributed data. Using this approach, we developed a protocol collaboratively that was then adapted and implemented at each of the network's participating sites. ${ }^{13}$

\section{Data sources}

Canada has a publicly funded health care system that is administered provincially, with government drug insurance plans varying by province; CNODES has data-sharing agreements with 7 provinces (BC, Alberta, Saskatchewan, Manitoba, Ontario, Quebec and Nova Scotia). ${ }^{12}$ Two Canadian CNODES sites were unable to participate in the present study: Quebec had data-access delays, and, at the time of study initiation, Nova Scotia drug data were limited to individuals aged 65 years and older. Data from Ontario were limited to recipients of social assistance.

From the 5 included provinces, we used linked, individuallevel data on hospitalizations, physician visits, medication dispensations and vital status. Data sources were linked at the individual level using unique encoded identifiers derived from each person's health insurance number. The data sources are highly complete and accurate, ${ }^{14,15}$ and are used extensively in pharmacoepidemiology. ${ }^{12}$ Data sources used at each site are described in Appendix 1, Supplemental Table 1 (available at www.cmajopen.ca/content/9/2/E500/suppl/DC1).

\section{Study population}

In each province, we identified a cohort of all pregnancies ending with a hospital-delivered live birth between Apr. 1, 2004, and Sept. 30, 2017. The discharge date defined cohort entry. Exclusion criteria were maternal age less than 15 or greater than 55 years at cohort entry; less than 365 days of database history before conception (defined using the recorded gestational age or, if missing, defined as 273 days before term births and 245 days before preterm births ${ }^{16}$ ); health insurance coverage ending on or before cohort entry; no record of a newborn discharged alive; duplicate pregnancies caused by overlapping records or records reclassified as having outcomes other than live birth after the adjudication of overlapping records; a domperidone dispensing in the year before conception or during pregnancy (unless in the 6 months immediately after a previous birth); a diagnosis of Parkinson disease, Lewy body disease or other diseases that cause autonomic dysfunction or use of antiparkinsonian agents ${ }^{17}$ before cohort entry; a diagnosis of gastroparesis in the year before conception or during pregnancy; and a diagnosis of V'T before cohort entry.

Patients were followed until an event or censoring because of death, a diagnosis of an approved indication for domperidone (Parkinson disease or gastroparesis), emigration from the province, end of the 6-month follow-up or end of the study period (Sept. 30, 2017), whichever occurred first. Patients were permitted to contribute more than 1 observation.

\section{Exposure}

Exposure was defined using a time-fixed approach in which all observations were classified by the presence or absence of any dispensing for domperidone during the 6-month follow-up; previous studies suggest that most patients who start domperidone postpartum do so within the first 2 months. ${ }^{3}$ In the safety analyses, exposure was defined using a time-varying approach; all person-moments of follow-up were classified as currently exposed or not currently exposed to domperidone. Current exposure was defined by a domperidone dispensation for which its duration plus a 7-day grace period overlapped with the day of follow-up being classified.

\section{Outcome}

The primary safety outcome was a composite end point of VT or sudden cardiac death, with a composite end point used to increase precision. The 3-step procedure used to identify VT or sudden cardiac death is described in Appendix 1, Supplemental Figure 1. Briefly, cases of a first recorded VT or sudden cardiac death were identified as possible events. The administrative data of these patients were then manually reviewed by reviewers blinded to patient domperidone use, to confirm that the events met the definition of $\mathrm{VT}$ or sudden cardiac death. The date of the first recorded VT diagnosis or sudden cardiac death defined the event date. Secondary outcomes were the individual end points of VT, sudden cardiac death and all-cause mortality.

The algorithm used International Classification of Diseases, 9th Revision (ICD-9-CM) and the Canadian version of International Statistical Classification of Disease and Related Health Problems, 10th Revision (ICD-10-CA) diagnostic codes in all sites, with Ontario also using modified ICD- 8 codes ${ }^{18-20}$ The 
diagnostic codes used are reported in Appendix 1, Supplemental Table 2.

\section{Statistical analysis}

Characteristics of patients who did and did not use domperidone were summarized at each site. The definitions used to operationalize these characteristics are reported in Appendix 1, Supplemental Table 3. We defined the prevalence of use as the percentage of patients who received a domperidone dispensation in the 6 months postpartum, with analyses stratified by province and by calendar period (2003-2005, 20062008, 2009-2011, 2012-2014 and 2015-2017). We described use overall, by dosage (>30 mg/d v. $\leq 30 \mathrm{mg} / \mathrm{d}$ ) and by duration (>14 d v. $\leq 14 \mathrm{~d}$ ) of the first treatment episode, defined by the prescription duration or, in the case of multiple prescriptions, their duration allowing for up to a 7-day gap between the end of one prescription and the start of the next.

We used interrupted time series analysis ${ }^{21}$ to assess the impact of the Mar. 2, 2012, and Jan. 20, 2015, Health Canada advisories ${ }^{9,10}$ on prescribing practices, comparing the rate of initiation before versus after the advisories with the estimates we would have expected to observe in their absence. We estimated the rate of domperidone initiation by quarter. We then used generalized least squares models that allow for a first-order autoregressive structure (to account for correlation between consecutive quarters) to examine the immediate impact and change in slope (i.e., trend) associated with the advisories. The impact of the advisories was examined overall, by dosage and by duration of the first treatment episode. In addition, we described the dosage and duration distributions before and after each advisory. Saskatchewan prescription data contained quantity dispensed but not duration, and we were unable to assume World
Health Organization-defined daily doses ${ }^{22}$ to estimate duration as we were studying off-label use. We therefore used the mean daily dose from Ontario to estimate duration in Saskatchewan. Province-specific results were pooled using DerSimonian and Laird random-effects models, ${ }^{23}$ with the amount of betweenprovince heterogeneity estimated using the $I^{2}$ statistic.

We had planned to assess the cardiac safety of domperidone using a prevalent new-user design. ${ }^{24}$ However, given the small number of events in each province, this approach was deemed infeasible. Consequently, we estimated crude rate ratios and rate differences for each outcome across provinces, with exposure defined using the previously described timevarying approach.

In post-hoc sensitivity analyses, we repeated our interrupted time series analyses with a dependent variable of $\ln$ (prescription rate) to estimate relative reductions in geometric means at the time of the advisories. In addition, we repeated analyses using linear models rather than interrupted time series analyses to explore the impact of our choice of model structure on model fit.

\section{Ethics approval}

Research ethics board approvals were obtained at each participating institution, except at ICES in Ontario, where research ethics board approval was not legally required.

\section{Results}

A total of 1190987 pregnancies (Figure 1) ended with a live birth from 801959 patients (Appendix 1, Supplemental Figure 2). Patients had been exposed to domperidone in 137401 observations and had not been exposed in 1053586 observations. Table 1 and Appendix 1, Supplemental Table 4

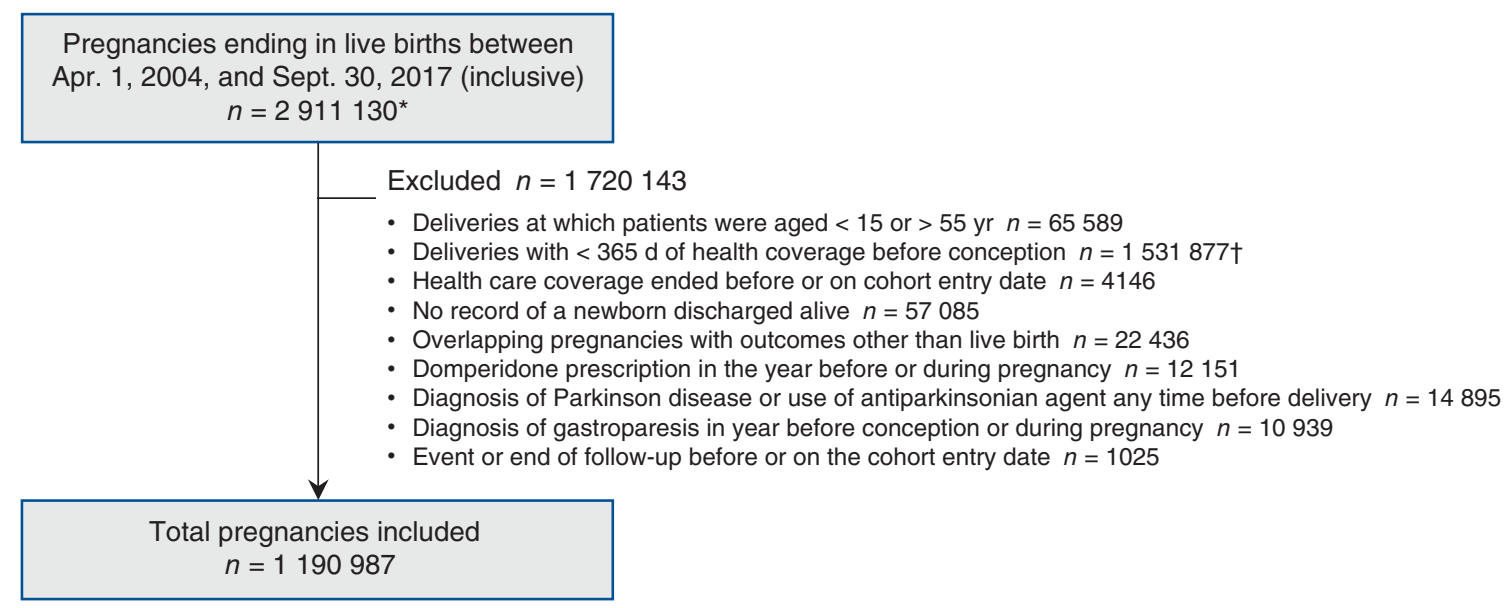

Figure 1: Flow diagram describing the construction of the study cohort across provinces, by pregnancy. *Patients were eligible to contribute multiple pregnancies to the study cohort. †The exclusion of observations with less than 365 days of health coverage was predominantly driven by Ontario, where the study population was restricted to patients receiving social assistance. Patients excluded in this step in Ontario included those who did not receive social assistance for at least 365 days before conception. 
Table 1: Baseline characteristics of deliveries overall and by use of domperidone in the 6 months immediately postpartum*

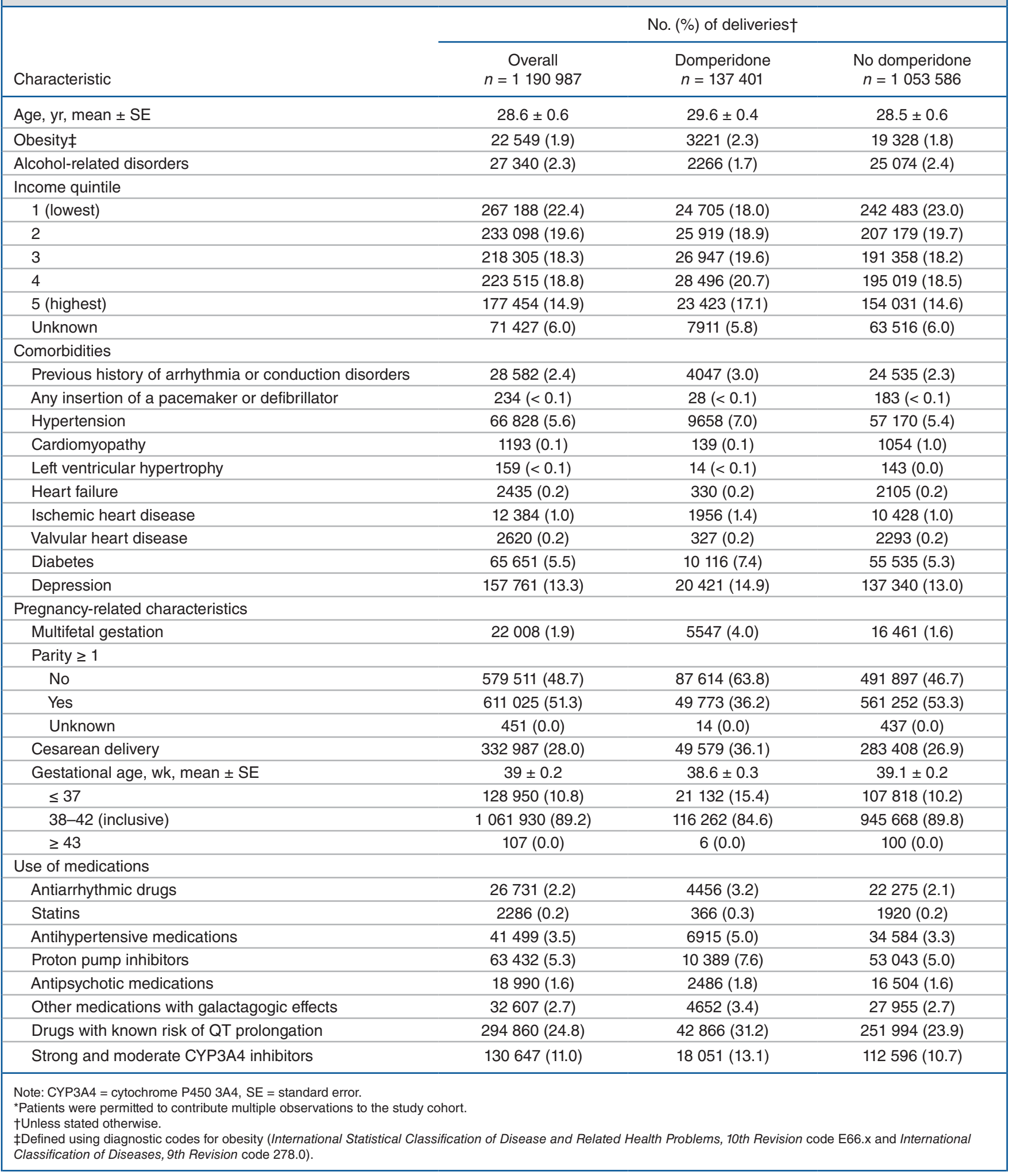

summarize the characteristics of the cohort overall and by exposure status. Compared with patients not using domperidone, patients using domperidone were older, more likely to be obese, more likely to reside in higher socioeconomic areas and less likely to have alcohol-related disorders. Although the cohort was generally healthy, patients using domperidone had a higher prevalence of medication use and comorbidities, including risk factors for cardiac arrhythmias. Patients using 
domperidone were also more likely to have had a multifetal gestation, cesarean delivery, premature birth and gestational complications during the cohort entry-defining pregnancy.

\section{Drug utilization}

Figure 2 and Appendix 1, Supplemental Figures 3-5 describe the prevalence of domperidone use in the 6 months postpartum between 2004 and 2017. Across provinces, postpartum use increased from $7 \%$ in $2003-2005$ to $12 \%$ in $2009-2011$, when it plateaued. Important interprovincial differences existed, with the greatest use observed in BC and Alberta and less frequent use in Saskatchewan, Manitoba and Ontario. The prevalence of use increased over time in most provinces, although small decreases were observed in later periods in $\mathrm{BC}$ and Alberta. The prevalence of use ranged from $2 \%$ in Saskatchewan to $10 \%$ in BC in 2003-2005 and from 6\% in Manitoba to $14 \%$ in BC in 2015-2018. Similar patterns were observed when analyses were restricted to use of dosages greater than $30 \mathrm{mg} / \mathrm{d}$ and durations greater than 14 days (Appendix 1, Supplemental Figures 4 and 5).

\section{Impact of Health Canada advisories}

The results of our interrupted time series analyses are reported in Figures 3 and 4, and in Appendix 1, Supplemental Figures 6-15. After the 2012 advisory there was an immediate drop of 11.5 initiators per 100000 person-days at the time of the advisory and a reduction in slope of initiation of 0.8 initiators per 100000 person-days per quarter (Figure 3).
Similar trends were observed for doses greater than $30 \mathrm{mg}$ and durations greater than 14 days (Appendix 1, Supplemental Figures 6 and 7). Changes after the 2015 advisory were more modest (Figure 4; Appendix 1, Supplemental Figures 7 and 8).

Appendix 1, Supplemental Tables 5 and 6 summarize the dosage and duration of the first domperidone treatment episode among initiators by province and by period. Overall, among those dispensed domperidone, the dosage decreased across periods in each province. However, the median dosage remained greater than $30 \mathrm{mg} / \mathrm{d}$ in all provinces after the advisories. The median duration was 30 days in most provinces, which remained unchanged after the advisories.

The results of sensitivity analyses examining the relative reductions are found in Appendix 1, Supplemental Tables 7 and 8 . This approach reduced the heterogeneity across sites and improved model fit relative to the primary analysis, but similar trends were observed as in our primary analysis. In addition, in all scenarios, the Akaike information criterion (AIC) for the interrupted time series analysis was smaller than the AIC for the linear model, indicating better model fit (Appendix 1, Supplemental Tables 9 and 10).

\section{Cardiac events}

Appendix 1, Supplemental Table 11 describes the overall incidence rates across the 5 provinces. Events were rare (22 composite events, 13 VTs, 10 sudden cardiac deaths and 168 all-cause deaths), with rates ranging from 0.18 (95\% CI 0.09

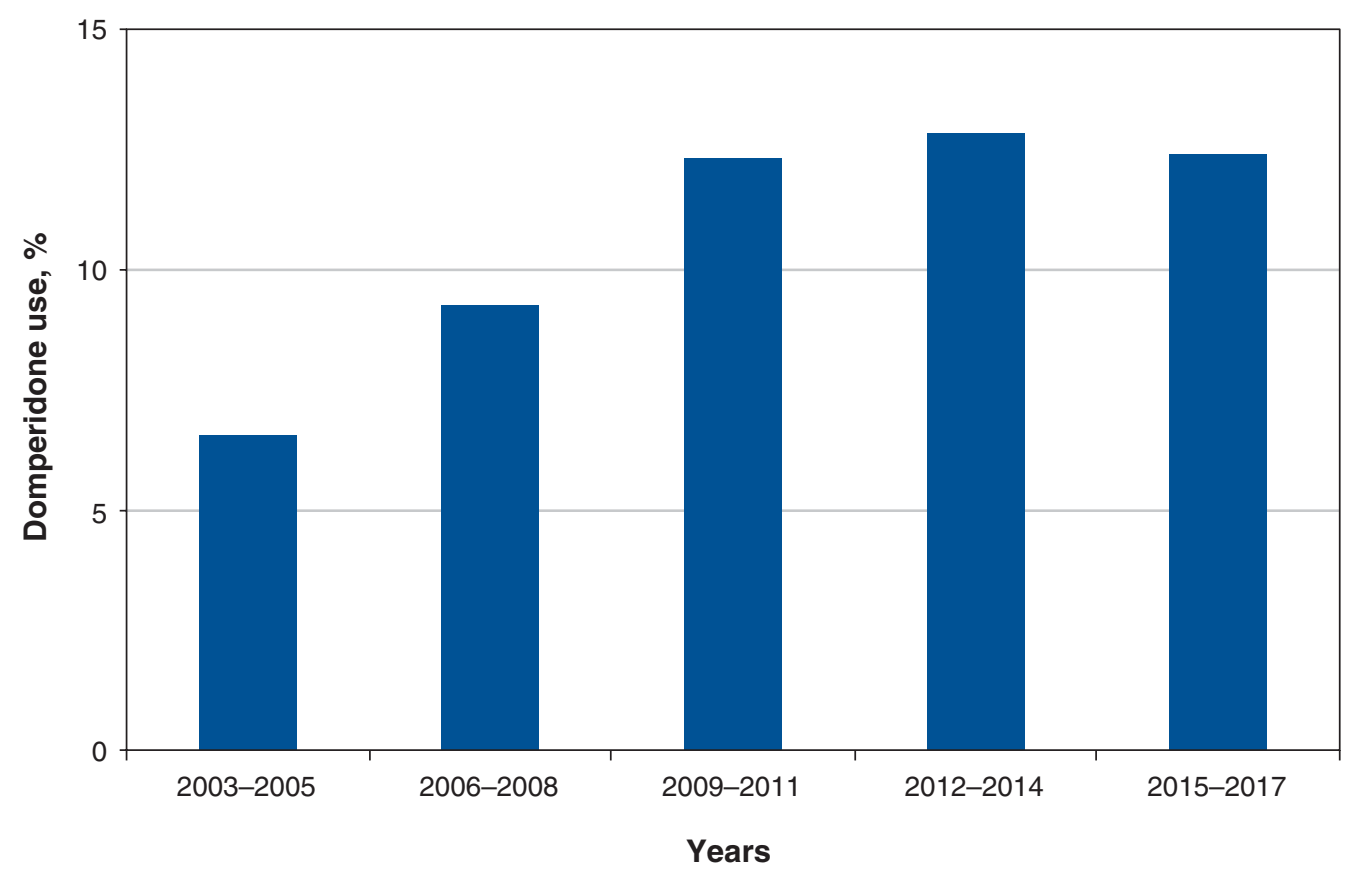

Figure 2: Prevalence of domperidone use in the 6 months after delivery among postpartum patients in 5 Canadian provinces. Health Canada advisories regarding domperidone were issued in March 2012 and January 2015. 


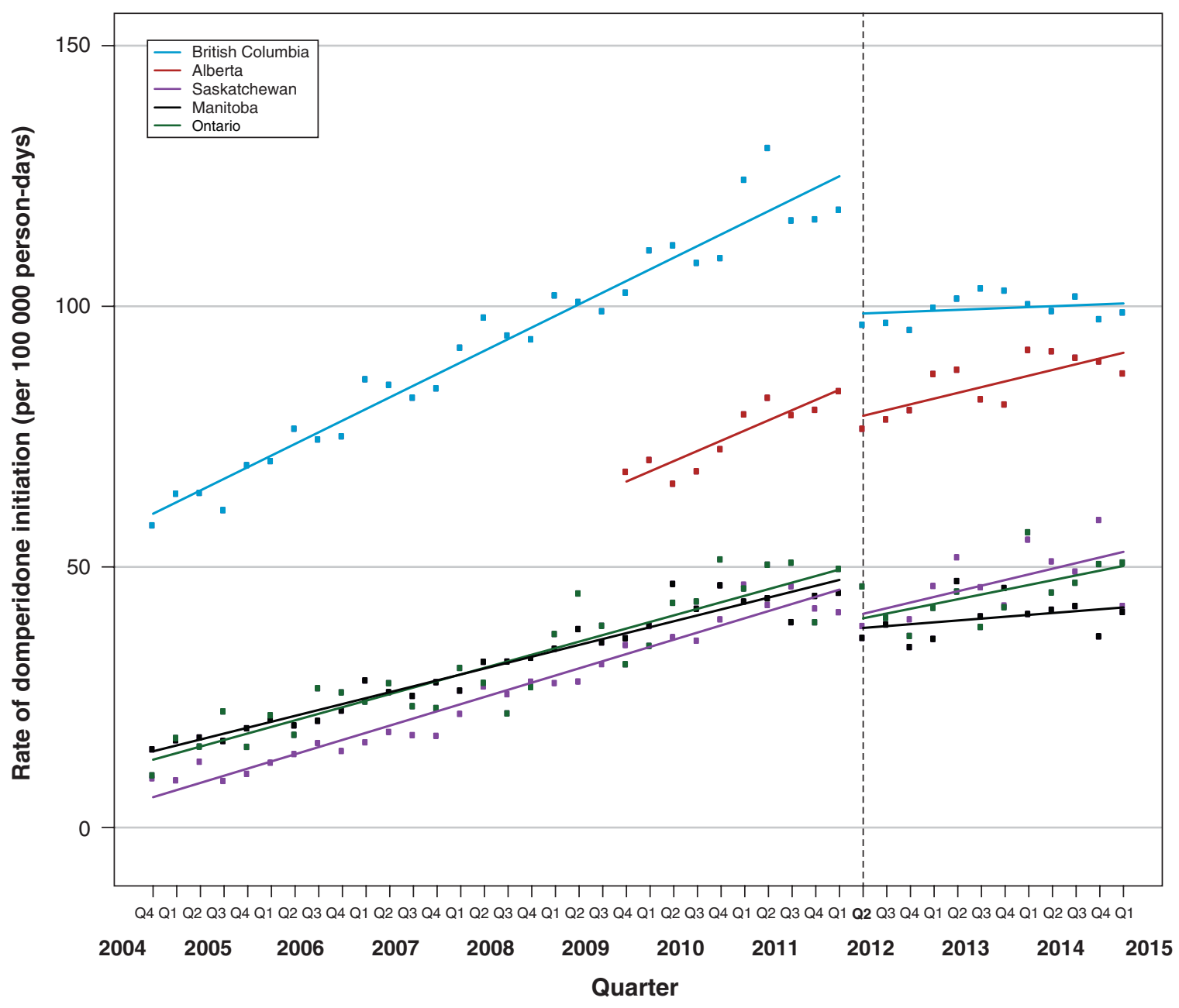

\begin{tabular}{|c|c|c|}
\hline Province & $\begin{array}{l}\text { Immediate impact } \\
(95 \% \mathrm{Cl})^{*}\end{array}$ & $\begin{array}{c}\text { Change in slope } \\
(95 \% \mathrm{Cl}) \dagger\end{array}$ \\
\hline British Columbia & $-26.5(-33.0$ to -20.0$)$ & $-2.1(-2.9$ to -1.3$)$ \\
\hline Alberta & $-6.1(-12.5$ to 0.3$)$ & $-0.9(-2.0$ to 0.3$)$ \\
\hline Saskatchewan & $-5.7(-10.6$ to -0.9$)$ & $-0.3(-0.9$ to 0.3$)$ \\
\hline Manitoba & $-9.6(-13.9$ to -5.2$)$ & $-0.8(-1.3$ to -0.2$)$ \\
\hline Ontario & $-10.3(-17.3$ to -3.2$)$ & $-0.3(-1.2$ to 0.5$)$ \\
\hline All provinces & $\begin{array}{c}-11.5(-18.9 \text { to }-4.2) \\
P^{2}=88.2 \% \\
\mathrm{Tau}^{2}=61.8\end{array}$ & $\begin{array}{c}-0.8(-1.5 \text { to }-0.2) \\
{ }^{2}=72.2 \% \\
\operatorname{Tau}^{2}=0.356\end{array}$ \\
\hline
\end{tabular}

Figure 3: Interrupted time series analysis examining the impact of the 2012 Health Canada advisory on rates of initiation of domperidone in the 6 months immediately postpartum in 5 Canadian provinces. The dashed line represents the release of the 2012 Health Canada advisory. Note: $\mathrm{Cl}=$ confidence interval.

to 0.33$)$ per 10000 person-years for sudden cardiac death to 2.95 (95\% CI 2.54 to 3.44 ) per 10000 person-years for allcause mortality. Table 2 summarizes the rates of our safety end points by current domperidone use. Crude incidence rates for our composite end point of $\mathrm{VT}$ or sudden cardiac death were numerically higher with current use of domperi- done than with no current use (crude rate ratio 2.01, 95\% CI 0.47 to 8.60 ; crude rate difference $0.37,95 \% \mathrm{CI}-0.67$ to 1.41 per 10000 person-years). In contrast, all-cause mortality was lower with current domperidone use (crude rate ratio 0.37 , $95 \%$ CI 0.12 to 1.15 ; rate difference $-1.93,95 \%$ CI -3.28 to -0.59 per 10000 person-years). 


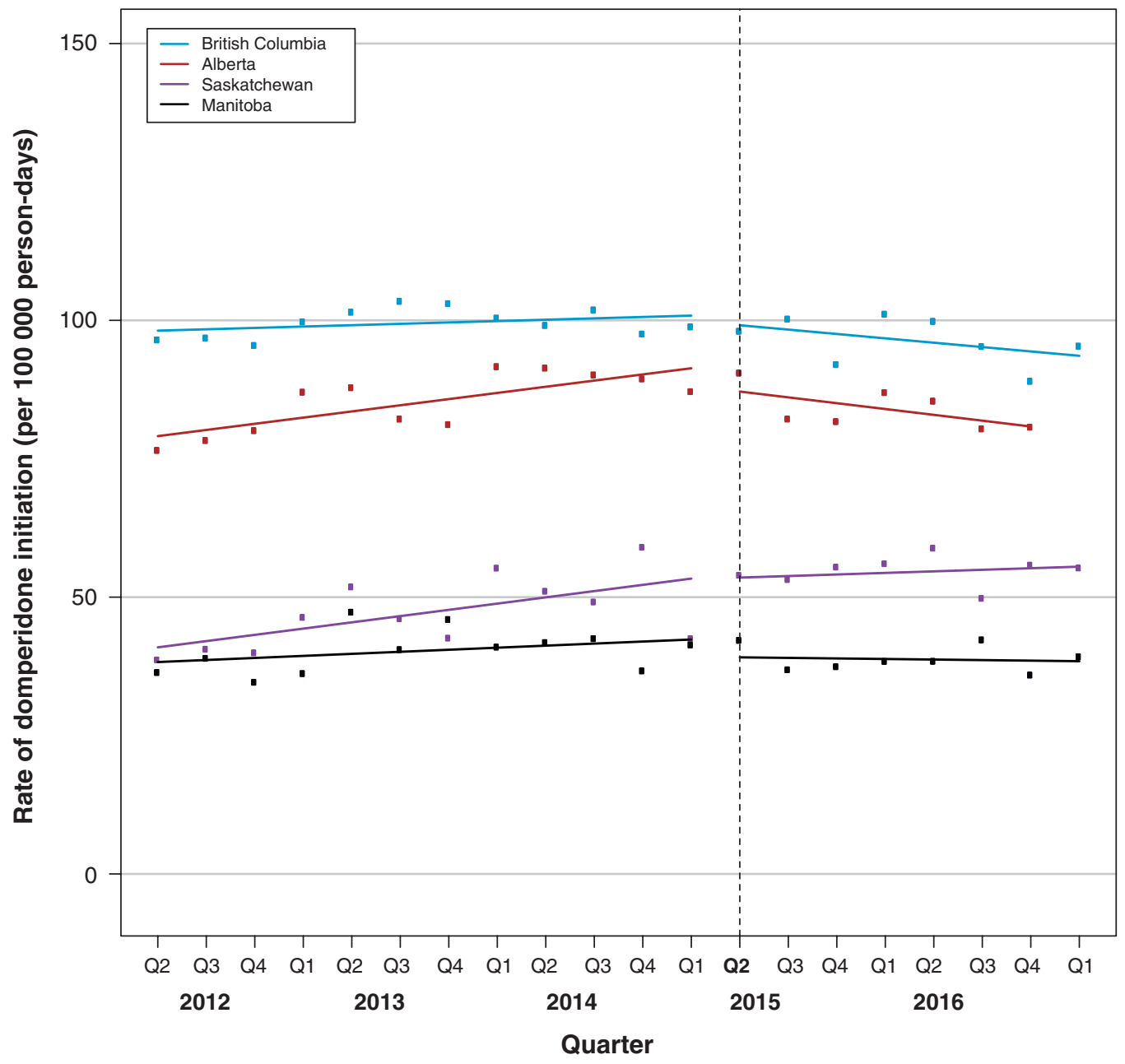

\begin{tabular}{|l|c|c|}
\hline Province & $\begin{array}{c}\text { Immediate impact } \\
(95 \% \mathrm{Cl})^{*}\end{array}$ & $\begin{array}{c}\text { Change in slope } \\
(95 \% \mathrm{Cl}) \dagger\end{array}$ \\
\hline British Columbia & $-0.9(-7.1$ to 5.2$)$ & $-1.0(-2.2$ to 0.1$)$ \\
\hline Alberta & $-3.2(-10.1$ to 3.8$)$ & $-2.2(-3.6$ to -0.7$)$ \\
\hline Saskatchewan & $-0.1(-6.8$ to 6.6$)$ & $-0.8(-2.0$ to 0.3$)$ \\
\hline Manitoba & $-3.1(-9.0$ to 2.8$)$ & $-0.5(-1.5$ to 0.6$)$ \\
\hline All provinces & $-1.9(-5.0$ to 1.3$)$ & $-1.0(-1.6$ to -0.4$)$ \\
\multicolumn{2}{|c|}{$\left.\right|^{2}=0.0 \%$} & $0.33 \%$ \\
Tau ${ }^{2}=0.00$ & Tau $^{2}=0.001$ \\
\hline $\begin{array}{l}\text { *Impact is measured in initiators per } 100000 \text { person-days. } \\
\text { †Change in slope is measured in initiators per } 100000 \text { person-days per quarter. }\end{array}$
\end{tabular}

Figure 4: Interrupted time series analysis examining the impact of the 2015 Health Canada advisory on rates of initiation of domperidone in the 6 months immediately postpartum in 4 Canadian provinces. Ontario was excluded from this analysis owing to insufficient data available postadvisory. The dashed line represents the release of the 2015 Health Canada advisory. Note: $\mathrm{Cl}=$ confidence interval.

\section{Interpretation}

Our study was designed to assess off-label domperidone use among postpartum patients in Canada. We found that use was prevalent in this population, increasing substantially between 2004 and 2017 (7\% in 2003-2005 until a plateau at
$12 \%$ in 2009-2011 that persisted through 2015-2017). The 2012 Health Canada advisory ${ }^{9}$ was associated with a reduction in prescribing overall and of dosages greater than $30 \mathrm{mg} / \mathrm{d}$ and durations greater than 14 days. The 2015 advisory ${ }^{10}$ was associated with a more modest impact on prescribing. The safety analysis indicated a relatively higher risk of 


\begin{tabular}{|c|c|c|c|}
\hline Variable & $\begin{array}{l}\text { Incidence rate } \\
\qquad(95 \% \mathrm{Cl})^{*}\end{array}$ & $\begin{array}{l}\text { Crude rate ratio } \\
\qquad(95 \% \mathrm{Cl})\end{array}$ & $\begin{array}{l}\text { Crude rate difference } \\
\qquad(95 \% \mathrm{Cl})^{\star}\end{array}$ \\
\hline \multicolumn{4}{|l|}{$\begin{array}{l}\text { Composite of VT or sudden cardiac } \\
\text { death }\end{array}$} \\
\hline Current domperidone use & 0.74 (0.19 to 2.97$)$ & $2.01(0.47$ to 8.60$)$ & $0.37(-0.67$ to 1.41$)$ \\
\hline No current domperidone use & 0.37 (0.24 to 0.57$)$ & 1.00 (Ref.) & 0.00 (Ref.) \\
\hline \multicolumn{4}{|l|}{ VT } \\
\hline Current domperidone use & 0.74 (0.19 to 2.97$)$ & $3.66(0.81$ to 16.49$)$ & $0.54(-0.50$ to 1.57$)$ \\
\hline No current domperidone use & 0.20 (0.11 to 0.37$)$ & 1.00 (Ref.) & 0.00 (Ref.) \\
\hline \multicolumn{4}{|l|}{ Sudden cardiac death } \\
\hline Current domperidone use & 0.00 (0.00 to 0.00$)$ & - & $-0.18(-0.30$ to -0.07$)$ \\
\hline No current domperidone use & 0.18 (0.10 to 0.34$)$ & 1.00 (Ref.) & 0.00 (Ref.) \\
\hline \multicolumn{4}{|l|}{ All-cause mortality } \\
\hline Current domperidone use & $1.11(0.36$ to 3.45$)$ & $0.37(0.12$ to 1.15$)$ & $-1.93(-3.28$ to -0.59$)$ \\
\hline No current domperidone use & 3.05 (2.61 to 3.55$)$ & 1.00 (Ref.) & 0.00 (Ref.) \\
\hline
\end{tabular}

VT or sudden cardiac death among patients using domperidone than among those not using domperidone. However, the crude nature of these analyses and sparse data limit the conclusions that can be drawn from these findings.

We observed interprovincial variation in domperidone prescriptions. These differences approximate the prevalence of breastfeeding during the study period, ${ }^{25,26}$ suggesting that differences in the prevalence of breastfeeding may be at least partially responsible for the observed interprovincial differences. Given our use of administrative data, we were unable to restrict inclusion to patients who were breastfeeding. Ultimately, the observed interprovincial differences are likely explained by a combination of differences in prescribing practices, health care access, patient preferences and breastfeeding practices.

The impact of regulatory warnings concerning domperidone has been examined previously outside of Canada. ${ }^{27}$ Mehrabadi and colleagues found that the EMA advisory regarding domperidone was associated with decreased prescribing of dosages greater than $30 \mathrm{mg} / \mathrm{d}$, a nonsignificant decrease in monthly prescriptions and no change in time trend in the United Kingdom. ${ }^{27}$ Importantly, although the Health Canada advisories were followed by decreased rates of initiation at higher dosages and decreased median dosage in all provinces in our study, the median dosage in all provinces exceeded the recommended dosages of no more than $30 \mathrm{mg} / \mathrm{d}$ after the advisories. .10

Mehrabadi and colleagues found that the rate of initiation of domperidone increased from 2002-2004 (0.56 per 100 person-years) to 2011-2013 (2.1 per 100 person-years), before dropping slightly in 2014-2015 (2.0 per 100 person-years) after the EMA advisory. ${ }^{27}$ Domperidone use among postpartum patients was also assessed in an Australian tertiary teach- ing hospital, which reported that $5 \%$ of patients were dispensed domperidone, with use increasing during the 2004-2008 study period. ${ }^{28}$

Smolina and colleagues found that domperidone may increase the risk of ventricular arrhythmias or cardiac arrest (HR 2.25, 95\% CI 0.84 to 6.01 ) using BC data. ${ }^{11}$ Our utilization analyses described similar trends but included 4 additional provinces and up to 6 years of more contemporary data. Although we identified fewer events, this is likely the result of differences in event definitions, with Smolina and colleagues also including atrial arrhythmia codes and the present study restricting events to those considered sudden and unexpected, and using exposure grace periods. Despite these differences, the estimates reported by Smolina and colleagues are compatible with our estimates (crude rate ratio $2.01,95 \%$ CI 0.47 to 8.60). The rates of VT and sudden cardiac death among patients using domperidone reported in the present study are higher than those reported by Mehrabadi and colleagues, ${ }^{27}$ who reported no exposed ventricular arrhythmias, cardiac arrests or sudden cardiac deaths. Importantly, although our analysis suggests that domperidone may increase VT or sudden cardiac death risk, estimates are crude and imprecise. Although this analysis suggests a potential doubling of the risk, the absolute risk in this population remains very small. Our analyses also suggest a potential decreased risk of allcause mortality, but this observation may be explained by confounding. Ultimately, given the unadjusted nature of these analyses, they should be interpreted very cautiously.

\section{Limitations}

Our study has several limitations. Data on prescription drug claims do not contain information regarding indication. 
Although we excluded patients with approved indications for domperidone, it is possible that some patients were using it for indications other than lactation. Data regarding alcohol consumption and smoking status were not available. Also, data regarding breastfeeding were not systematically captured. Exposure misclassification is possible as data are not available regarding medication consumption. Assessment of VT and sudden cardiac death in administrative databases is challenging, and outcome misclassification is therefore possible. The limited number of events did not allow for formal safety analyses. Our interrupted time series analyses may also have been affected by unmeasured confounders (e.g., other changes in guidelines or clinical practice occurring around the time of the advisories). Finally, there were differences across sites in data availability. Ontario data were restricted to recipients of social assistance, and the generalizability of trends observed in this population to others is unknown. Vital statistics data were not available in Saskatchewan, and only partial emergency department data were available, potentially resulting in incomplete event capture.

\section{Conclusion}

The use of domperidone among postpartum patients increased substantially between 2004 and 2017, though variations existed across provinces. The 2012 Health Canada advisory was followed by important changes in prescribing practices across provinces, whereas the 2015 advisory had a more modest impact on prescribing. Our safety analysis showed a crude rate of VT or sudden cardiac death that was relatively higher among those using domperidone than among those not using domperidone. However, owing to sparse data and the lack of statistical adjustment, these results should be interpreted with caution. Nonetheless, the absolute rate of $\mathrm{VT}$ or sudden cardiac death is low in this population, and although a potential increased risk could not be confirmed in this large study, it should be discussed when considering treatment options for individual patients.

\section{References}

1. Barone JA. Domperidone: a peripherally acting dopamine2-receptor antagonist. Ann Pharmacother 1999;33:429-40.

2. Campbell-Yeo ML, Allen AC, Joseph KS, et al. Effect of domperidone on the composition of preterm human breast milk. Pediatrics 2010;125:e107-14.

3. Smolina K, Morgan SG, Hanley GE, et al. Postpartum domperidone use in British Columbia: a retrospective cohort study. CMA7 Open 2016;4:E13-9.

4. Johannes CB, Varas-Lorenzo C, McQuay LJ, et al. Risk of serious ventricular arrhythmia and sudden cardiac death in a cohort of users of domperidone: a nested case-control study. Pharmacoepidemiol Drug Saf 2010;19:881-8.

5. Paul C, Zenut M, Dorut A, et al. Use of domperidone as a galactagogue drug: a systematic review of the benefit-risk ratio. $\mathcal{F}$ Hum Lact 2015;31:57-63.

6. van Noord C, Dieleman JP, van Herpen G, et al. Domperidone and ventricular arrhythmia or sudden cardiac death: a population-based case-control study in the Netherlands. Drug Saf 2010;33:1003-14.

7. Straus SM, Sturkenboom MC, Bleumink GS, et al. Non-cardiac QTcprolonging drugs and the risk of sudden cardiac death. Eur Heart 72005 ; 26:2007-12.

8. Renoux C, Dell'Aniello S, Khairy P, et al. Ventricular tachyarrhythmia and sudden cardiac death with domperidone use in Parkinson's disease. Br 7 Clin Pharmacol 2016;82:461-72.

9. Domperidone maleate - association with serious abnormal heart rhythms and sudden death (cardiac arrest) - for health care professionals. Ottawa: Health Canada; 2012. Available: www.healthycanadians.gc.ca/recall-alert-rappel-avis/ hc-sc/2012/15857a-eng.php (accessed 2020 Dec. 15).

10. Domperidone maleate - association with serious abnormal heart rhythms and sudden death (cardiac arrest) — for health professionals. Ottawa: Health
Canada; 2015. Available: www.healthycanadians.gc.ca/recall-alert-rappel-avis/ hc-sc/2015/43423a-eng.php (accessed 2020 Dec. 15).

11. Smolina K, Mintzes B, Hanley GE, et al. The association between domperidone and ventricular arrhythmia in the postpartum period. Pharmacoepidemiol Drug Saf 2016;25:1210-4.

12. Suissa S, Henry D, Caetano P, et al. CNODES: the Canadian Network for Observational Drug Effect Studies. Open Med 2012;6:e134-40.

13. Sengwee T, Pratt N, Klungel O, et al. Distributed networks of databases analyzed using common protocols and/or common data models. In: Strom BL, Kimmel SE, Hennessy S, editors. Pharmacoepidemiology. 6th ed. Hoboken (NJ): John Wiley \& Sons; 2019:617-38.

14. Levy AR, O'Brien BJ, Sellors C, et al. Coding accuracy of administrative drug claims in the Ontario Drug Benefit database. Can 7 Clin Pharmacol 2003;10: 67-71.

15. Juurlink DPC, Croxford R, Chong A, et al. Canadian Institute for Health Information Discharge Abstract Database: a validation study. Toronto: Institute for Clinical Evaluative Sciences; 2006.

16. Eberg M, Platt RW, Filion KB. The estimation of gestational age at birth in database studies. Epidemiology 2017;28:854-62.

17. Parkes JD. Domperidone and Parkinson's disease. Clin Neuropharmacol 1986; 9:517-32.

18. International classification of diseases, 9th revision, [Clinical Modification] (ICD9-CM). Geneva: World Health Organization; [updated 2015 Nov. 6].

19. Canadian coding standards for version 2018 ICD-10-CA and CCI. Ottawa: Canadian Institute for Health Information; 2004.

20. International classification of diseases and related bealth problems (ICD-11). Geneva: World Health Organization; 2020. Available: www.who.int/ standards/classifications/classification-of-diseases (accessed 2020 Dec. 15).

21. Penfold RB, Zhang F. Use of interrupted time series analysis in evaluating health care quality improvements. Acad Pediatr 2013;13(Suppl):S38-44.

22. WHO Collaborating Centre for Drug Statistics Methodology. A: Alimentary tract and metabolism. A03: Drugs for functional gastrointestinal disorders. Available: www.whocc.no/atc_ddd_index/?code=A03FA03 (accessed 2018 Aug. 20).

23. DerSimonian R, Laird N. Meta-analysis in clinical trials. Control Clin Trials 1986;7:177-88.

24. Suissa S, Moodie EE, Dell'Aniello S. Prevalent new-user cohort designs for comparative drug effect studies by time-conditional propensity scores. Pharmacoepidemiol Drug Saf 2017;26:459-68.

25. Health characteristics, annual estimates [Table 13-10-0096-01]. Ottawa: Statistics Canada; 2020. Available: www150.statcan.gc.ca/t1/tbl1/en/tv.action?pid $=1310009601$ (accessed 2019 July 11).

26. Gionet L. Breastfeeding trends in Canada Statistics Canada. Ottawa: Statistics Canada; 2015. Cat no 82-624-X. Available: www150.statcan.gc.ca/n1/pub/82 -624-X/2013001/article/11879-eng.htm (accessed 2019 June 21).

27. Mehrabadi A, Reynier P, Platt RW, et al. Domperidone for insufficient lactation in England 2002-2015: a drug utilization study with interrupted time series analysis. Pharmacoepidemiol Drug Saf 2018;27:1316-24.

28. Grzeskowiak LE, Dalton JA, Fielder AL. Factors associated with domperidone use as a galactogogue at an Australian tertiary teaching hospital. 7 Hum Lact 2015;31:249-53.

Affiliations: Centre for Clinical Epidemiology (Moriello, Reynier, Aibibula, Filion), Lady Davis Institute, Jewish General Hospital, McGill University, Montréal, Que; ICES (Paterson); Institute of Health Policy, Management and Evaluation (Paterson), University of Toronto, Toronto, Ont.; Manitoba Centre for Health Policy, Department of Community Health Sciences (Dahl, Kuo), Max Rady College of Medicine, Rady Faculty of Health Sciences, University of Manitoba, Winnipeg, Man.; Department of Anesthesiology, Pharmacology and Therapeutics (Fisher), University of British Columbia, Vancouver BC; School of Pharmacy (Gamble), University of Waterloo, Kitchener, Ont.; Department of Community Health Sciences (Ronksley), Cumming School of Medicine, University of Calgary, Calgary, Alta.; Saskatchewan Health Quality Council (Winquist); Department of Community Health and Epidemiology (Winquist), College of Medicine, University of Saskatchewan, Saskatoon Sask.; Departments of Medicine and of Epidemiology, Biostatistics, and Occupational Health (Filion), McGill University, Montréal, Que.

Contributors: Carolina Moriello and Kristian Filion drafted the manuscript. All authors contributed to the study design and implementation, and interpretation of results, and critically reviewed the manuscript for important intellectual content. All authors gave final approval of the version to be published and agreed to be accountable for all aspects of the work.

*The Canadian Network for Observational Drug Effect Studies (CNODES) Investigators: Samy Suissa (principal investigator); Colin R. Dormuth (British Columbia); Brenda R. Hemmelgarn (Alberta); 
Jacqueline Quail (Saskatchewan); Dan Chateau (Manitoba); J. Michael Paterson (Ontario); Jacques LeLorier (Quebec); Adrian R. Levy (Atlantic: Nova Scotia, Newfoundland and Labrador, New Brunswick, Prince Edward Island); Pierre Ernst and Kristian B. Filion (UK Clinical Practice Research Datalink); Lisa M. Lix (database); Robert W. Platt (methods); and Ingrid S. Sketris (knowledge translation)

Funding: The Canadian Network for Observational Drug Effect Studies, a collaborating centre of the Drug Safety and Effectiveness Network (DSEN), is funded by the Canadian Institutes of Health Research (grant no. DSE-146021).

Content licence: This is an Open Access article distributed in accordance with the terms of the Creative Commons Attribution (CC BY-NC-ND 4.0) licence, which permits use, distribution and reproduction in any medium, provided that the original publication is properly cited, the use is noncommercial (i.e., research or educational use), and no modifications or adaptations are made. See: https://creativecommons.org/licenses/by-nc-nd/4.0/

Data sharing: This study was conducted by CNODES using administrative health data obtained through data-sharing agreements between its member research centres and their respective provincial data stewards. Although these data-sharing agreements prohibit CNODES from making the study data sets publicly available, certain CNODES research centres may grant access to individuals who meet prespecified criteria for confidential access. For details, please contact the corresponding author.

Acknowledgements: The authors acknowledge the programming contributions of Richard Morrow (British Columbia), Jianguo Zhang (Alberta), Xinya Lu (Saskatchewan) and Fangyun Wu (Ontario).

This study was made possible through data-sharing agreements between CNODES member research centres and the respective provincial governments of Alberta, BC, Manitoba (HIPC \# 2018/2019-17), Ontario and Saskatchewan. The BC Ministry of Health and the BC Vital Statistics Agency approved access to and use of BC data facilitated by Population Data BC for this study. British Columbia data sources were as follows (https://www2.gov.bc.ca/gov/content/health/conducting-healthresearch-evaluation/data-access-health-data-central): British Columbia Ministry of Health [creator] (2017): Medical Services Plan (MSP) Payment Information File. BC Ministry of Health [publisher]. MOH (2017); British Columbia Ministry of Health [creator] (2017): PharmaNet. BC Ministry of Health [publisher]. Data Stewardship Committee (2017); Canadian Institute for Health Information [creator] (2017): Discharge Abstract Database (Hospital Separations). BC Ministry of Health [publisher]. MOH (2017); British Columbia Ministry of Health [creator] (2017): Consolidation File (MSP Registration \& Premium Billing). BC Ministry of Health [publisher]. MOH (2017); BC Vital Statistics Agency [creator] (2017): Vital Statistics Deaths. V2. BC Ministry of Health [publisher]. Vital Statistics Agency (2017). BC Vital Statistics Agency [creator] (2017): Vital Statistics Births. V2. BC Ministry of Health [publisher]. Vital Statistics Agency (2017). Parts of this material are based on data and/or information compiled and provided by the Canadian Institute for Health information. The opinions, results and conclusions reported in this paper are those of the authors. No endorsement by the funders, data providers, data stewards or Health Canada is intended or should be inferred.

Kristian Filion is supported by a senior salary support award from the Fonds de recherche du Québec - santé and a William Dawson Scholar award from McGill University.

Supplemental information: For reviewer comments and the original submission of this manuscript, please see www.cmajopen.ca/content/9/2/ E500/suppl/DC1. 